\title{
Determination of the effective mode-I toughness of a sinusoidal interface between two elastic solids
}

\author{
Pablo D. Zavattieri • Louis G. Hector Jr. • \\ Allan F. Bower
}

Published online: 30 October 2007

(C) Springer Science+Business Media B.V. 2007

\section{Erratum to: Int J Fract 145:3, pp. 167-180 (2007) DOI 10.1007/s10704-007-9109-y}

Due to an unfortunate turn of events this article has been published with an erroneous version of Figure 3, an erroneous version of Equation 6 and also two errors in the text of the second paragraph of Section 3.1 "Influence of cohesive interface properties". Please find below the correct Figure 3, Equation 6 and text part of the second paragraph of Section 3.1 that should be regarded by the reader as the final versions.

$$
\frac{K_{I c}}{K_{0}}=\Gamma\left(\frac{\sigma_{\max }}{E}, \frac{\delta_{n}}{\lambda}, \frac{\tau_{\max }}{\sigma_{\max }}, q, v, \frac{A}{\lambda}\right)
$$

\section{(3.1 Influence of cohesive interface properties)}

Perhaps the most intriguing observation results when the same analysis is plotted in terms of $l_{c z} / \lambda$ as in Fig. 6 . When $\sigma_{\max }$ and $\delta_{n}$ are varied, $l_{c z}$ varies according to Eq. 8. The role of $\sigma_{\max }$ and $\delta_{n}$ in controlling the conditions necessary to initiate crack propagation and cause failure can be illustrated more clearly by plotting the variation of $K_{\text {init }} / K_{0}$ (solid curve with open circles) and $K_{I c} / K_{0}$ (dashed line with solid circles) with the normalized cohesive zone length $l_{c z} / \lambda$.

The online version of the original article can be found under doi:10.1007/s10704-007-9109-y.

P. D. Zavattieri $(\varangle) \cdot$ L. G. Hector Jr.

GM Research and Development Center, Warren,

MI 48090, USA

e-mail: Pablo.Zavattieri@gm.com

\section{A. F. Bower}

Division of Engineering,

Brown University, Providence,

RI 02912, USA 


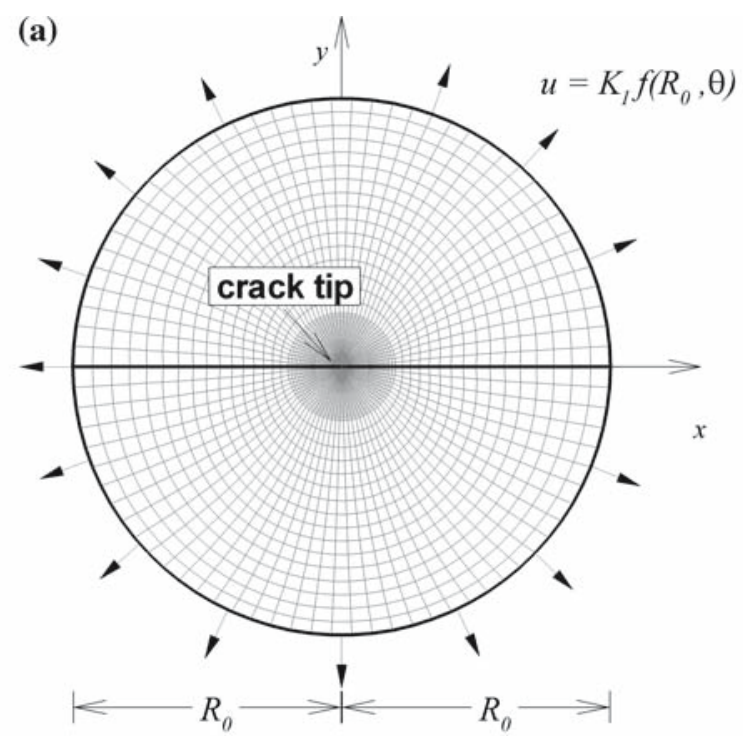

(b)

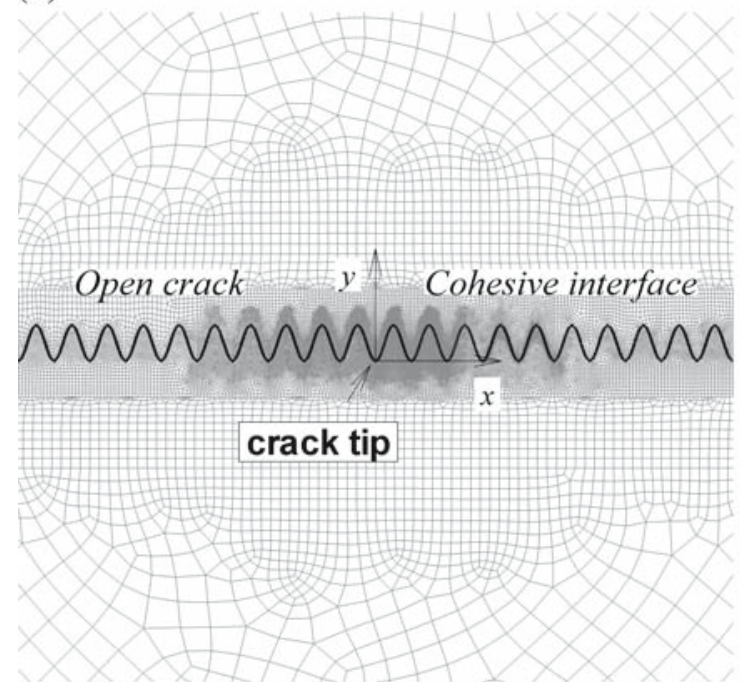

(c)

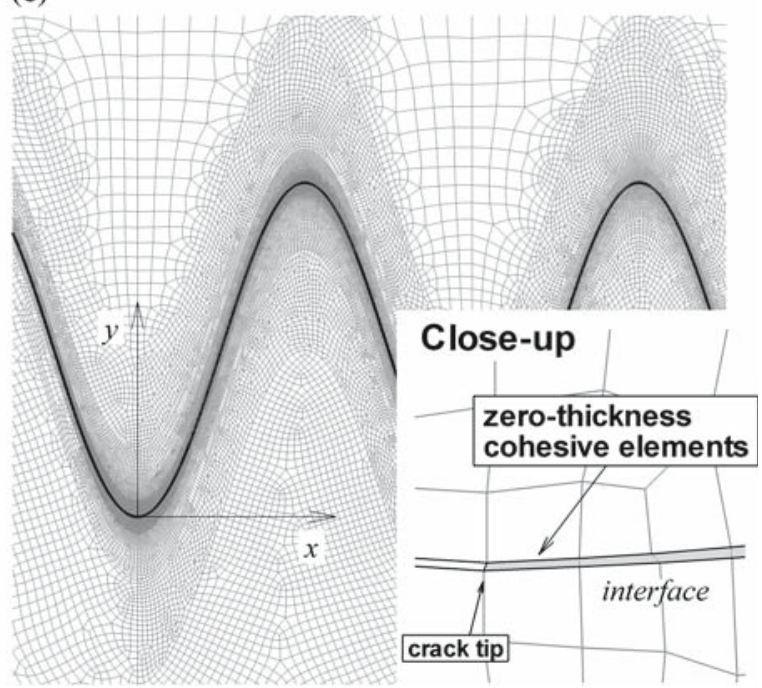

Fig. 3 (a) Sample mesh with $R_{0}>A$. The sinusoidal interface is center of the mesh along the $x$-axis and hence is not visible. (b) Zoom showing the sinusoidal interface and the crack tip. (c) Region near the crack tip and exploded view showing the cohesive elements 